\title{
EFFECT OF CHRONIC HYPOTHALAMIC STIMULATION UPON CHOLESTEROL-INDUCED ATHEROSCLEROSIS IN THE RABBIT *
}

\author{
By C. G. GUNN, MEYER FRIEDMAN AND SANFORD O. BYERS
(From the Departments of Medicine and Physiology, University of Oklahoma Medical Center, Oklahoma City, Okla., and the Harold Brunn Institute, Mount Zion Hospital and \\ Medical Center, San Francisco, Calif.)
}

(Submitted for publication July 11, 1960; accepted August 18, 1960)

The possible role of the central nervous system (CNS) in the pathogenesis of experimental atherosclerosis has received scant investigative scrutiny. Indeed, it can even be stated that the majority of investigators in the field of experimental atherosclerosis are frankly skeptical of any possible etiological relationship between dysfunction of any central neural mechanisms and peripheral atherosclerosis. Certainly in most of the recent American reviews concerned with atherosclerosis the subject of nervous factors in the etiology of atherosclerosis has either been minimized or totally neglected.

Despite this seeming exclusion of the CNS from laboratory studies of atherosclerosis by many investigators, certain experimental and clinical data make this neglect appear rather unfortunate. Myasnikov $(1,2)$ has demonstrated that when drugs that depress certain CNS mechanisms (e.g., barbiturates) were chronically given to cholesterolfed rabbits, these rabbits exhibited a significant decrease in hypercholesterolemia and aortic atherosclerosis. On the other hand, phenamine, a drug which excites the CNS, produced the opposite effects, increasing the hypercholesterolemia and atherosclerosis (3). Finally, it has been reported that rats fed an atherogenic diet and exposed to a particular form of stress exhibited greater degrees of hypercholesterolemia and coronary atherosclerosis than their controls fed the same diet (4).

Several clinical studies also strongly suggest that changes in psychological behavior influence not only the level of blood cholesterol (5-8) but also the incidence of clinically manifested coronary artery disease (9).

\footnotetext{
* Aided by grants from the Alameda County Heart Association, Life Insurance Medical Research Fund, and the National Heart Institute (H-3111 and H-119), Bethesda, Md.
}

If these experimental and clinical reports are valid, they force us, despite their paucity, to include the CNS in the ambit of investigation concerning the pathogenesis of atherosclerosis.

This report describes some effects of chronic minimal electrical stimulation discretely delivered to electrodes placed in the diencephalon of rabbits fed a cholesterol-rich diet. It was found that rabbits exposed to such stimulation exhibited a significantly greater degree of hyperlipemia and a much more marked atherosclerotic involvement of their aortic and coronary vasculature than did their controls.

\section{METHODS}

The present study was the result of a joint effort by individuals of the University of Oklahoma Medical Center (C. G. G.) and of the Harold Brunn Institute, Mount Zion Hospital and Medical Center, San Francisco (M. F. and S. O. B.). All physiological and anatomical procedures were done at the University of Oklahoma Medical Center, while all biochemical and pathological studies were carried out at the Harold Brunn Institute. In order to eliminate bias, all biochemical and pathological data were obtained, assessed and recorded blind, i.e., without knowledge of whether a given specimen was from an experimental or control animal.

Thirty-five male New Zealand white rabbits of the same age and comparable size from the same inbred herd were chosen at a large breeding farm. After an observation period of 1 month, 19 of these animals were operated upon under pentobarbital anesthesia. By means of a stereotaxic instrument (10), electrodes were inserted into or as close as possible to the ventral medial nucleus of the hypothalamus. The electrodes were small, bipolar, concentric and insulated from each other except at the tip. The bare electrode tips were separated from each other by a distance of $1 \mathrm{~mm}$. After insertion, the electrodes and their subminiature plug attachment were secured to the calvarium with dental cement. The subcutaneous tissue and skin then were closed in layers leaving the plug outside (see Figure 1) and available for connection to either recording or stimulating apparatus. 


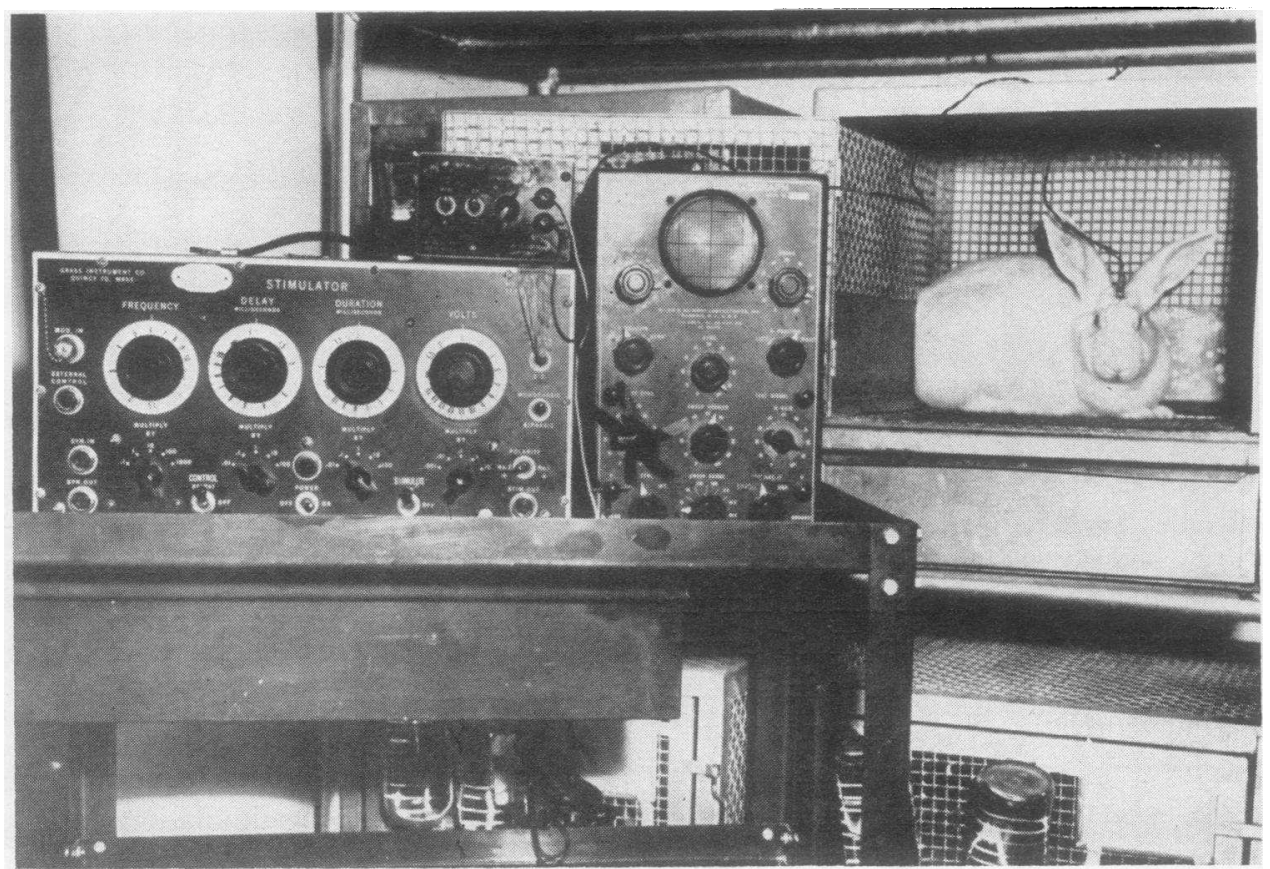

Fig. 1. Rabbit with implanted electrodes connected to stimulator. The oscilloscope monitors (voltage or milliamperage) the parameters of stimulation. When not in use, external wires and plug are removed without touching the animal.

Following the operation, the animals were rested for 1 month. In order to determine the behavioral and autonomic thresholds, preliminary studies were done utilizing biphasic, 60 cycles per second, monitored currents of 0.2 to $0.8 \mathrm{ma}$. The current was administered at a strength of 1 to $6 \mathrm{v}$ in pulses of $0.2 \mathrm{msec}$ duration.

The threshold parameter (i.e., the current necessary to produce pupillary and behavioral changes) was determined for each of the 19 animals. Then they were given chronic stimulations at a current strength slightly above the determined threshold. These chronic stimulations were done four times daily, 6 days a week for 3 months. Each period or "epoch" of stimulation consisted of ten 30 -second episodes of actual stimulation interspersed with ten 30 -second intervals of pause. The voltage and amperage of each stimulation were monitored with an oscilloscope to ensure constancy. All stimulations were done in the cage without direct handling of the animal (see Figure 1). The daily behavior and response of each rabbit to stimulation were recorded.

Three series of animals were studied for 3 months. Series A consisted of 14 of the 19 animals bearing electrodes, that were placed on Purina rabbit chow enriched with cottonseed oil (1 per cent) and cholesterol (1 per cent) immediately following operation. Series B consisted of the remaining 5 of these 19 stimulated rabbits that were placed on Purina rabbit chow alone. Series C, a control group, consisted of 16 intact rabbits that were given the cholesterol- and oil-enriched diet.

Stimulation in the medial areas of the hypothalamus in cats has been reported to induce satiety (11), thus care was taken in the present studies to ensure comparable intake of the lipid-enriched food by all of the animals. This was accomplished by restricting the food allotment for each animal to that quantity completely consumed by those rabbits eating least. This latter amount was approximately $100 \mathrm{~g}$ per day containing about 160 calories.

In order to discover possible effects of acute hypothalamic stimulation, some of the animals of the above series also were studied both before and very soon after a single episode of stimulation. Thus after the first month of the experiment, seven rabbits of Series $A$ and five of Series B were bled $(20 \mathrm{ml})$ and then stimulated for two continuous "epochs." One hour later, blood samples were again obtained. For control purposes, five rabbits of Series C were bled at the same time intervals. A similar study (except that the second blood sample was obtained 5 hours after acute stimulation) was repeated upon seven rabbits of Series $A$ at the end of 3 months. In this latter study, four rabbits of Series $C$ also were bled at the same time intervals.

In the chronic experiment, as distinguished from the above acute experiments, blood samples were obtained before the beginning of the experimental period and then repeated each month, as indicated in Table I. In most cases, blood samples were analyzed for serum cholesterol (12), phospholipid (13), total lipid (14), and 17-hydroxycorticosteroid (15).

At the end of the 3-month period, all animals were sacrificed by intravenous injection of air. The brain was removed, fixed in formalin, cut at $50 \mu$ and stained 


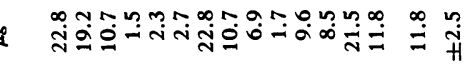

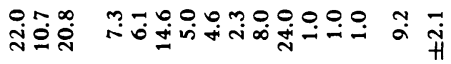

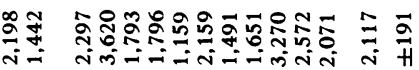

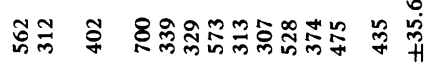

\section{minimiti}

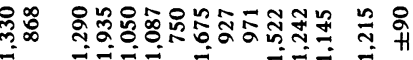

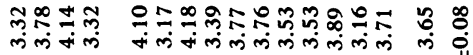

นดำ

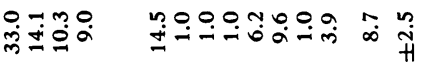

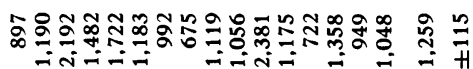

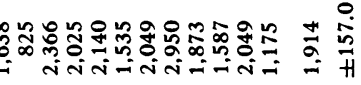

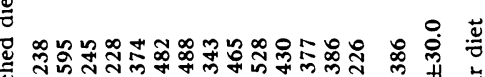
泀

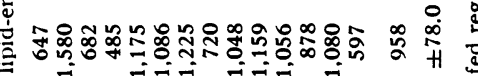
ก⿻ำ 2

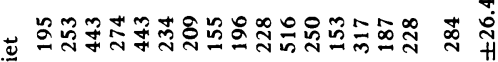

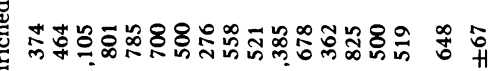

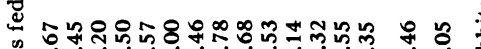

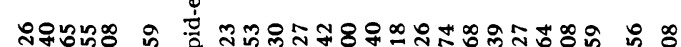

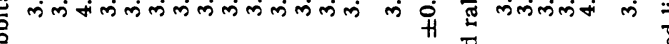
递

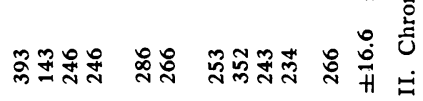

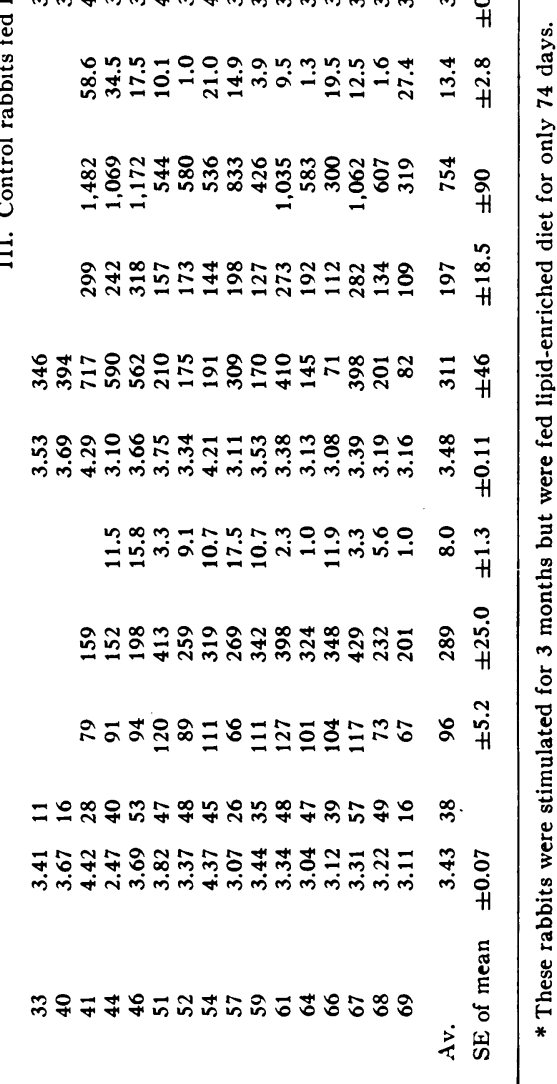


with thionin to determine the loci of the implanted electrodes.

The heart, total aorta and adrenals of each animal were obtained. The aorta was first inspected grossly and graded 0 to +5 (16) for its degree of atherosclerosis. In addition, an aortic segment of $10 \mathrm{~cm}$ beginning at the semilunar valves was routinely obtained and analyzed for its cholesterol content.

Three cross sections of the heart (base, middle and apex) were obtained and stained with Sudan IV. Then each cross section was studied as follows: the total number of large arteries (i.e., vessels exhibiting well defined adventitia, media and intima) were counted; the total number exhibiting sudanophilic intimal hyperplasia occupying 20 per cent or more of the lumen were also counted. The percentage of the total number of large arteries in each cross section showing sudanophilia of the required degree was then calculated. A final percentage of sudanophilia for each heart was obtained by averaging the three individual percentages calculated from each of the three cross sections. Similar observations and calculations were made of the medium-sized and small coronary arteries encountered in the same three cross sections.

The adrenals were weighed. Sections also were obtained from the adrenal glands of four stimulated and three nonstimulated rabbits ingesting the lipid-enriched diet. These were stained with both Sudan IV and hematoxylin and eosin.

All animals were housed in similar cages in the same room with the temperature controlled between $61^{\circ}$ to $71^{\circ}$ F. Electroencephalograms were taken monthly of each stimulated animal. Blood pressure determinations (by direct arterial puncture) were obtained initially and then every month of the experimental period.

Thirty-four of the 35 rabbits survived the experimental period of 3 months.

\section{RESULTS}

A. Loci of hypothalamic stimulation. Histological examination of the brains of the 14 stimulated rabbits fed the lipicl-enriched diet revealed (see Table I and Figure 2) that the locus of the stimulating electrodes was in or near the ventral medial nucleus hypothalamicus (VMH) in six rabbits, the anterior hypothalamic area (AHA) in three, the lateral hypothalamic area (LHA) in two, the supra-opticus diffusus (SOD) in two, and the nucleus arcuatus periventricularis $(\mathrm{ARC})$ in the remaining rabbit.

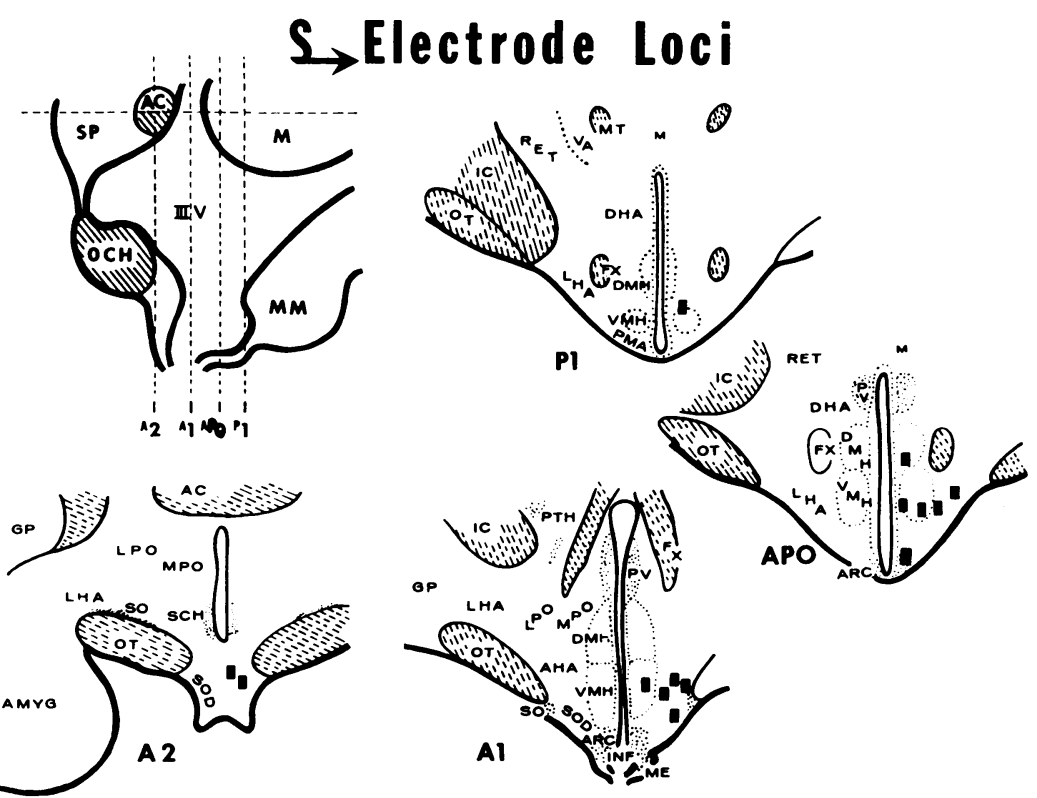

Fig. 2. Diagram illustrating the site of electrode emplacement in the 14 experimental rabrits. Solid rectangles show electrode positions in the coronal-section diagrams corresponding to the planes on the midsagittal schematic (upper left-hand diagram with dashed lines showing coronal planes) through hypothalamic area (10). Coronal planes are $1 \mathrm{~mm}$ apart. $\mathrm{OCH}=$ optic chiasm; $\mathrm{MM}=$ mammillary bodies; III $\mathrm{V}=$ third ventricle; $\mathrm{DMH}=$ dorsal medial nucleus hypothalamus; $\mathrm{VMH}=$ ventral medial nucleus hypothalamicus; $\mathrm{LHA}=$ lateral hypothalamic area; $\mathrm{AHA}=$ anterior hypothalamic area $; \mathrm{SOD}=$ supra-opticus diffusus nucleus; $\mathrm{ARC}=$ nucleus arcuatus periventricularis. 
Histological examination of the brains of the five stimulated rabbits fed the stock diet revealed that the locus of the stimulating electrodes was in the $\mathrm{VMH}$ in three of the rabbits; the locus in the remaining two rabbits was in the mesencephalic reticular formation (MesRF).

B. Behavioral and physiological observations during stimulation and thereafter. When not actually receiving stimulation, all rabbits in any of the chronically stimulated groups exhibited behavior that was identical with that of the nonoperated controls. The EEG records were in conformity with this judgment of normality of behavior between periods of stimulation, since no permanent EEG abnormality was observed in the chronically stimulated animals. The behavioral threshold to stimulation remained fairly constant for all rabbits during the total experimental period.

Nevertheless, during, and sometimes immediately after an "epoch" of stimulation marked changes in behavior could be observed in the stimulated rabbits. During stimulation almost all animals exhibited pupillary dilatation. Those rabbits whose electrodes were found embedded in the $\mathrm{VMH}, \mathrm{LHA}$ or AHA exhibited rather characteristic differences in behavior from the three rabbits whose electrodes were found implanted in the SOD or ARC. The former group showed increased activity with random searching and circling in the cage; they also would display licking and chewing movements and some would ingest food avidly during and only during a phase of stimulation within an "epoch." These behavioral and gustatory changes were most marked in those animals whose electrodes were in or near the VMH. The latter group, three rabbits whose electrodes were placed in the SOD or ARC, usually displayed a decrease both in the rate and in the amplitude of respiration; moreover, they usually (but not invariably) remained totally immobile for the duration of the applied current. Rarely they also exhibited eating, licking or chewing movements either during or immediately after stimulation.

No significant chronic change in blood pressure was observed in either the experimental or the control groups given the lipid-enriched food. The average blood pressure of the control group of rabbits was $116 \mathrm{~mm} \mathrm{Hg}$ (mean pressure) at the beginning of the experiment and $114 \mathrm{~mm} \mathrm{Hg}$ at the end. The average blood pressure of the stim- ulated rabbits for the same two periods was 113 and $117 \mathrm{~mm} \mathrm{Hg}$, respectively. However, stimulation did evoke a transient rise of 5 to $20 \mathrm{~mm} \mathrm{Hg}$ in five of seven rabbits tested shortly following an "epoch." It is of interest that the two rabbits that failed to show this pressor response were found to have their electrodes in either the anterior or posterior area of the medial eminence of the hypothalamus (SOD and ARC).

C. Changes in blood lipids and corticosteroids after chronic and acute hypothalamic stimulation. Despite the equivalence of age, amount of food ingested, and weight, the series of rabbits both chronically stimulated and also fed the lipidenriched diet displayed serum cholesterol, phospholipid and total lipid values that were considerably greater throughout the 3-month period than corresponding values in the nonstimulated rabbits fed the same lipid-enriched diet (see Table I). All increases were significant, with the $p$ value at the 0.01 level. On the other hand, rabbits that were chronically stimulated but given only the (relatively) lipid-poor stock diet (see Table I) failed to exhibit any significant change in their serum cholesterol levels.

It was of interest to us that apparently the lipid increases observed in the chronically stimulated rabbits ingesting the lipid-enriched diet appeared to be about equal in all of the rabbits, regardless of the exact site of electrode insertion. Thus, the average lipid values of the six rabbits having electrodes in their $\mathrm{VMH}$ were about the same during the 3-month period as those of rabbits having their electrodes in the AHA, LHA or SOD. The only exception was one animal (no. 55) whose stimulation was received in the ARC area and whose lipids after 3 months were similar to those of the controls.

A single acute stimulation, however, whether coming after either 1 or 3 months of chronic daily stimulation, failed to provoke any acute rise in the serum lipid values, irrespective of the nature of the diet (see Table II). Actually a slight fall usually was observed in the blood lipid values either at the 1 or 5 hour period after any particular stimulation. Since a similar slight fall also was observed in the nonstimulated controls, this may reflect a slight dilution of the plasma following the initial bleeding prior to stimulation.

The serum content of 17-hydroxycorticosteroids 


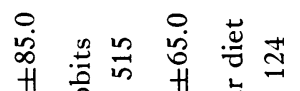

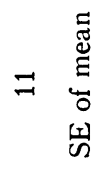

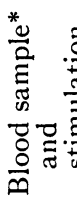

$-\quad$ 
failed to be influenced by either chronic (see lated rabbits fed the lipid-enriched diet as comTable I) or acute (see Table II) stimulation in either of the two stimulated series.

D. Pathological changes after chronic hypothalamic stimulation. No difference in heart size was observed in any of the three groups. However, striking differences in the degree of aortic atherosclerosis were exhibited by the chronically stimupared with the atherosclerosis shown by control nonstimulated rabbits fed the same quantities of the same diet (see Table III and Figure 3 ). Thus eight of the 14 stimulated rabbits showed moderate to marked aortic atherosclerosis (grade 2 or above), whereas only two of the 15 control animals showed a similar degree of involvement

TABLE III

Vascular and adrenal changes following chronic hypothalamic stimulation

\begin{tabular}{|c|c|c|c|c|c|c|}
\hline \multirow[b]{2}{*}{ Rabbit no. } & \multirow[b]{2}{*}{$\begin{array}{l}\text { Electrode } \\
\text { site }\end{array}$} & \multicolumn{2}{|c|}{ Aorta } & \multicolumn{2}{|c|}{$\begin{array}{c}\text { Per cent atherosclerotic } \\
\text { involvement } \\
\text { coronary vasculature }\end{array}$} & \multirow[b]{2}{*}{$\underset{\text { wt }}{\text { Adrenal }}$} \\
\hline & & $\begin{array}{c}\text { Gross } \\
\text { grading }\end{array}$ & Cholesterol & Large & Med. and small & \\
\hline \multicolumn{7}{|c|}{$\begin{array}{l}g / 100 \mathrm{~g} \\
\text { I. Chronically stimulated rabbits fed lipid-enriched diet }\end{array}$} \\
\hline $\begin{array}{l}35^{*} \\
37^{*} \\
48 \\
50 \\
60 \\
65 \\
34^{*} \\
47 \\
63 \\
39^{*} \\
53 \\
43 \\
62 \\
55\end{array}$ & $\begin{array}{l}\text { VMH } \\
\text { VMH } \\
\text { VMH } \\
\text { VMH } \\
\text { VMH } \\
\text { VMH } \\
\text { AHA } \\
\text { AHA } \\
\text { AHA } \\
\text { LHA } \\
\text { LHA } \\
\text { SOD } \\
\text { SOD } \\
\text { ARC }\end{array}$ & $\begin{array}{l}3.5 \\
5.0 \\
3.0 \\
3.0 \\
5.0 \\
1.0 \\
3.0 \\
1.0 \\
1.0 \\
3.0 \\
1.5 \\
1.0 \\
2.0 \\
1.0\end{array}$ & $\begin{array}{r}3.30 \\
7.37 \\
4.75 \\
5.52 \\
11.55 \\
8.17 \\
1.88 \\
2.96 \\
3.56 \\
2.69 \\
3.74 \\
2.02 \\
4.49 \\
2.83\end{array}$ & $\begin{array}{r}0 \\
43 \\
25 \\
50 \\
12 \\
75 \\
29 \\
10 \\
66 \\
14 \\
71 \\
57 \\
20 \\
0\end{array}$ & $\begin{array}{l}38 \\
14 \\
45 \\
37 \\
40 \\
42 \\
75 \\
43 \\
48 \\
54 \\
35 \\
33 \\
54 \\
10\end{array}$ & $\begin{array}{r}910 \\
750 \\
968 \\
1,205 \\
1,145 \\
2,145 \\
1,000 \\
1,452 \\
800 \\
975 \\
1,285 \\
1,040 \\
1,000 \\
1,318\end{array}$ \\
\hline $\begin{array}{l}\text { Average } \\
\text { SE of mean }\end{array}$ & & $\begin{aligned} & 2.4 \\
\pm & 0.37\end{aligned}$ & $\begin{array}{r}4.63 \\
\pm 0.70\end{array}$ & $\begin{array}{c}34 \\
\pm 6.8\end{array}$ & $\begin{array}{l}41 \\
\pm 4.1\end{array}$ & $\begin{array}{l}1,142 \\
\pm 84.0\end{array}$ \\
\hline \multicolumn{7}{|c|}{ II. Control nonstimulated rabbits fed lipid-enriched diet } \\
\hline $\begin{array}{l}33 \\
40 \\
41 \\
44 \\
51 \\
52 \\
54 \\
57 \\
59 \\
61 \\
64 \\
66 \\
67 \\
68 \\
69\end{array}$ & & $\begin{array}{l}0.5 \\
1.0 \\
4.0 \\
0.5 \\
1.0 \\
1.0 \\
0.5 \\
2.5 \\
0.5 \\
1.0 \\
0.5 \\
0.0 \\
0.0 \\
0.5 \\
0.0\end{array}$ & $\begin{array}{l}0.45 \\
1.66 \\
3.28 \\
1.61 \\
2.90 \\
2.85 \\
2.56 \\
3.72 \\
2.05 \\
4.12 \\
1.09 \\
1.00 \\
0.90 \\
0.72 \\
1.03\end{array}$ & $\begin{array}{r}25 \\
25 \\
22 \\
30 \\
33 \\
0 \\
0 \\
0 \\
33 \\
67 \\
0 \\
0 \\
40 \\
0 \\
0\end{array}$ & $\begin{array}{l}33 \\
17 \\
32 \\
42 \\
35 \\
24 \\
20 \\
15 \\
15 \\
39 \\
15 \\
17 \\
50 \\
18 \\
14\end{array}$ & $\begin{array}{r}1,235 \\
1,150 \\
1,570 \\
1,035 \\
930 \\
1,620 \\
1,010 \\
1,473 \\
785 \\
685 \\
745 \\
1,265 \\
865 \\
995 \\
910\end{array}$ \\
\hline $\begin{array}{l}\text { Average } \\
\mathrm{SE} \text { of mean }\end{array}$ & & $\begin{array}{l}0.9 \\
\pm 0.26\end{array}$ & $\begin{array}{ll} & 2.0 \\
\pm & 0.29\end{array}$ & $\begin{array}{l}18 \\
\pm 5.1\end{array}$ & $\begin{array}{l}26 \\
\pm 2.9\end{array}$ & $\begin{array}{l}1,085 \\
\pm 91.0\end{array}$ \\
\hline \multicolumn{7}{|c|}{ III. Chronically stimulated rabbits fed regular diet } \\
\hline $\begin{array}{r}3 \\
7 \\
9 \\
11 \\
16\end{array}$ & $\begin{array}{l}\text { MesRF } \\
\text { MesRF } \\
\text { VMH } \\
\text { VMH } \\
\text { VMH }\end{array}$ & $\begin{array}{l}0.0 \\
0.0 \\
0.0 \\
0.0 \\
0.0\end{array}$ & $\begin{array}{l}0.35 \\
0.30 \\
0.42 \\
0.22 \\
0.38\end{array}$ & $\begin{array}{l}\mathbf{0} \\
\mathbf{0} \\
\mathbf{0} \\
\mathbf{0} \\
\mathbf{0}\end{array}$ & $\begin{array}{l}0 \\
0 \\
0 \\
0 \\
0\end{array}$ & $\begin{array}{l}380 \\
600 \\
475 \\
700 \\
600\end{array}$ \\
\hline Average & & 0.0 & 0.33 & 0 & 0 & 551 \\
\hline
\end{tabular}

* These rabbits received lipid-enriched diet for only 74 days. -. 


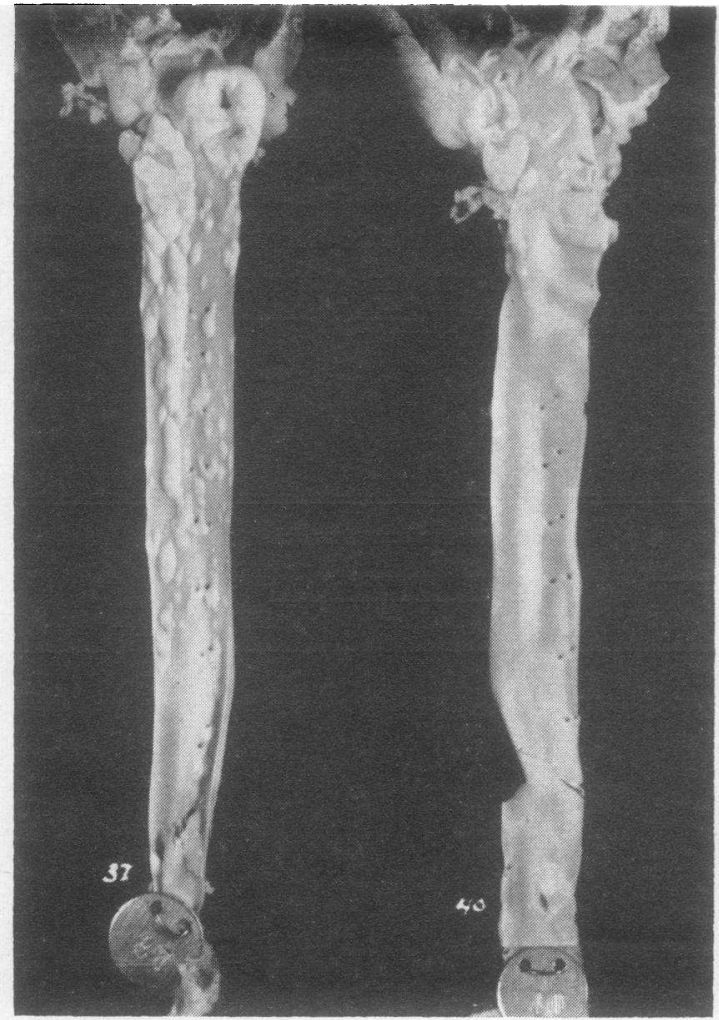

A

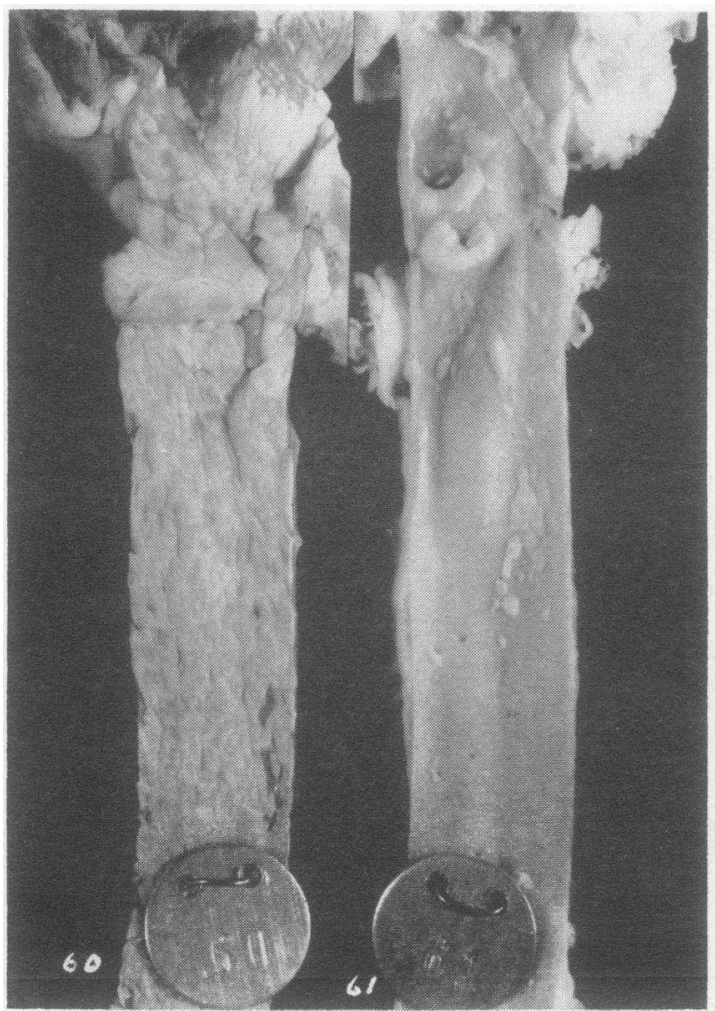

C

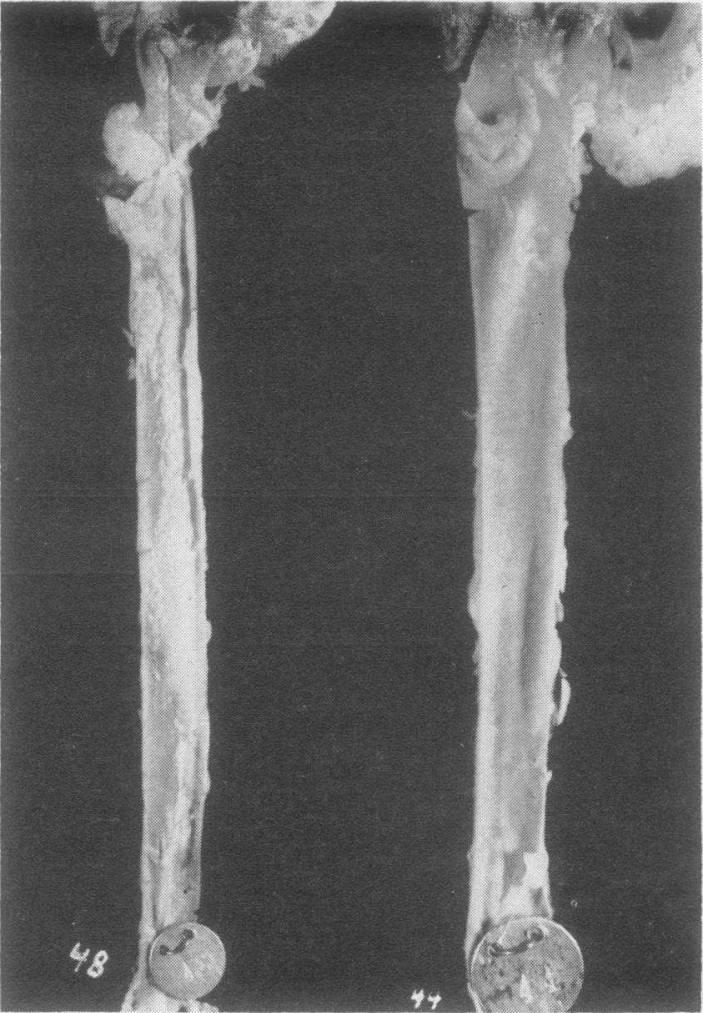

$\mathrm{B}$

Fig. 3. Aortas of Stimulated and CONTrol NONSTIMULATED RABBITS FED CHOLESTEROL. The aorta on the left of each photograph is that of a stimulated rabbit, and the one on the right, of a nonstimulated rabbit of the same experiment. The greater degree of atherosclerotic involvement of the aortas of the stimulated rabbits can easily be seen. 
( $\mathrm{p}$ value significant at the 0.01 level). This difference observed by gross inspection was corroborated by analysis of the aortic segments for cholesterol content. Thus the average cholesterol concentration ( $4.63 \mathrm{~g}$ per $100 \mathrm{~g}$ of dry weight) of the 14 aortic segments of the stimulated rabbits was over twice that $(2.0 \mathrm{~g}$ per $100 \mathrm{~g}$ of dry weight) found in the control nonstimulated rabbits ingesting the same diet ( $\mathrm{p}$ value significant at 0.01 level). By the same token (see Table III), a greater percentage of the coronary vasculature of the stimulated rabbits was atherosclerotic as compared with the vasculature of the control group.

A comparison of the degree of aortic atherosclerosis with the diencephalic site of electrode emplacement strongly suggests that the animals receiving stimulation in or in the vicinity of the VMH had excess aortic atherosclerosis and cholesterol infiltration. Thus the average grade of aortic atherosclerosis found in these six animals was 3.3 as compared to the grade of 2.4 for the total group of experimental animals, and the average cholesterol content of their aortic segments was $6.76 \mathrm{~g}$ per $100 \mathrm{~g}$ dry weight as compared to $4.63 \mathrm{~g}$ for all experimental animals and $2.0 \mathrm{~g}$ for the controls. The relatively small number of animals studied, however, precludes the drawing of an absolute conclusion concerning the significance of this difference.

On the other hand, as Table III indicates, stimulation of the group of five rabbits that were not fed the lipid-enriched food failed to induce either grossly observed or chemically detected atherosclerosis.

We were unable to detect any histological difference in the adrenals of either the stimulated or the unstimulated rabbits fed the lipid-enriched diet. In both groups, the adrenals (see Table III) were greatly and, on the average, equally enlarged. This increase in size and weight appeared to be due to lipid and cholesterol deposition.

\section{DISCUSSION}

The preceding data appear to indicate that rabbits fed a diet excessive in cholesterol and cottonseed oil and, in addition, receiving chronic stimulation of their diencephalon in the vicinity of the ventral medial nucleus, the lateral and the anterior hypothalamic areas, will exhibit a greater degree of chronic lipemia and a greater degree of aortic and coronary atherosclerosis than their nonstimulated controls. Although we were impressed by the fact that apparently the highest degree of atherosclerosis was exhibited by the six animals that were found to have their stimulating electrodes fixed in the ventral medial nucleus, the small number of rabbits studied makes the conclusion of an association between atherosclerosis and stimulation of the ventral medial nucleus a tentative conclusion at best.

The mechanism(s) whereby this chronic stimulation may have brought about the observed changes in the arterial vessel walls remains to be elucidated. However, it seems clear from the above study that they were not mediated by changes in food intake, by chronic changes in blood pressure or in physical activity. Our failure to observe any change in the corticosteroid level of the serum either during the period of chronic stimulation or soon ( 1 to 5 hours) after acute stimulation suggests but does not prove that the adrenal glands of these rabbits did not play a very important role in the pathogenesis of the atherosclerosis found.

Perhaps the chronically sustained greater degree of lipemia observed in the stimulated animals was responsible for the more extensive aortic and coronary atherosclerosis found. Certainly this lipemia must have a significant role if only because identical hypothalamic stimulation of rabbits given ordinary rabbit laboratory chow failed to elicit any detectable change either in the blood lipids or in the arterial walls. The means whereby chronic diencephalic stimulation (under the conditions of the present study) might intensify the hyperlipemic response of rabbits fed controlled rations of lipid-enriched food also remains to be understood.

\section{SUMMARY}

Evidence has been presented consistent with the hypothesis that chronic electrical stimulation delivered to certain hypothalamic areas significantly intensifies both the rate of increase arid the amount of hyperlipemia in rabbits fed a lipid-enriched diet. Such animals also showed a much greater atherosclerotic involvement of their aortic and coronary vasculature than did control animals given a similar diet. Those rabbits receiving 
stimulation in or near the ventral medial nucleus appeared to exhibit no greater hyperlipemia but considerably more atherosclerosis than the animals stimulated elsewhere.

It is concluded that central nervous system mechanisms exist which, under certain conditions, are capable of significantly influencing arterial atherogenesis.

\section{ACKNOWLEDGMENT}

The authors wish to express their deep thanks to Horace W. Magoun, who in 1955 arranged for the initial collaboration of the two participating groups which made the present study. They also wish to thank Dr. Shirley St. George for the 17-hydroxycorticosteroid analyses.

\section{REFERENCES}

1. Myasnikov, A. L. Experimental data on prophylaxis of arteriosclerosis. Klin. Med. (Mosk.) 1954, 32, no. $6,9$.

2. Myasnikov, A. L. Influence of some factors on development of experimental cholesterol atherosclerosis. Circulation 1958, 17, 99.

3. Tsibekmakher, T. D. Effect of phenamine and luminal on blood cholesterol and cholesterol ethers. Ter. Arh. 1955, 27, no. 1, 48.

4. Uhley, H. N., and Friedman, M. Blood lipids, clotting and coronary atherosclerosis in rats exposed to a particular form of stress. Amer. J. Physiol. 1959, 197, 396.

5. Friedman, M., Rosenman, R. H., and Carroll, V. Changes in the serum cholesterol and blood clotting time in men subjected to cyclic variation of occupational stress. Circulation 1958, 17, 852.

6. Wertlake, P. T., Wilcox, A. A., Haley, M. I., and Peterson, J. E. Ralationship of mental and emo- tional stress to serum cholesterol levels. Proc. Soc. exp. Biol. (N. Y.) 1958, 97, 163.

7. Grundy, S. M., and Griffin, A. C. Effects of periodic mental stress on serum cholesterol levels. Circulation 1959, 19, 496.

8. Hammarsten, J. F., Cathey, C. W., Redmond, R. F., and Wolf, S. Serum cholesterol, diet and stress in patients with coronary artery disease (abstract). J. clin. Invest. 1957, 36, 897.

9. Friedman, M., and Rosenman, R. H. Association of specific overt behavior pattern with blood and cardiovascular findings. Blood cholesterol level, blood clotting time, incidence of arcussenilis, and clinical coronary artery disease. J. Amer. med. Ass. 1959, 169, 1286.

10. Sawyer, C. H., Everett, J. W., and Green, J. D. The rabbit diencephalon in stereotaxic coordinates. J. comp. Neurol. 1954, 101, 801.

11. Anand, B. K., and Dua, S. Feeding responses induced by electrical stimulation of the hypothalamus in cat. Indian J. med. Res. 1955, 43, 113.

12. Saifer, A., and Kammerer, O. F. Photometric determination of total cholesterol in plasma or serum by modified Liebermann-Burchard reaction. J. biol. Chem. 1946, 164, 657.

13. Zilversmit, D. B., and Davis, A. K. Microdetermination of plasma phospholipids by trichloroacetic acid precipitation. J. Lab. clin. Med. 1950, 35, 155.

14. Bragdon, J. H. Colorimetric determination of blood lipides. J. biol. Chem. 1951, 190, 513.

15. Silber, R. H., and Porter, C. C. The determination of 17,21-dihydroxy-20-ketosteroids in urine and plasma. J. biol. Chem. 1954, 210, 923.

16. Friedman, M., Byers, S. O., and Rosenman, R. H. Resolution of aortic atherosclerotic infiltration in the rabbit by phosphatide infusion. Proc. Soc. exp. Biol. (N. Y.) 1957, 95, 586. 